\title{
ARAŞTIRMA / RESEARCH \\ Üst gastrointestinal sistem endoskopisi yapılan hastalarda intestinal metaplazi ve Helikobakter pylori skorlarının karşılaştırılması
}

\author{
Comparison of intestinal metaplasia and Helicobacter pylori scores in patients \\ undergoing upper gastrointestinal endoscopy
}

\section{Uğur Kesici}

Beykent Üniversitesi Tip Fakültesi, Genel Cerrahi Anabilim Dalı, İstanbul, Turkey

Cukurova Medical Journal 2018;43(3):574-580

\begin{abstract}
Purpose: The aim of this study is toreveal the relationship between Helicobacter pylori (HP) and intestinal metaplasia (IM) in patients with upper gastrointestinal endoscopy due to dissipative complaints.

Materials and Methods: Patients aged 15-84 years who underwent upper gastrointestinal endoscopy were included in this study. Demographically age and sex of the patients and histopathologically IM and HP scores were recorded. Patients were divided into two groups, Group A and Group B, aged 15-49 and over 50 years old respectively. It was investigated whether there was correlation between IM and HP scores with regards to several variables.

Results: This study included 200 patients aged 15-84 years. In Group B patients, IM incidence was significantly higher. In HP negative patients; IM rate in patients in Group B was significantly higher than Group A. In male patients in Group B, IMS mild to moderate incidence was statistically significantly higher.

Conclusion: There are studies in the literature that show that there is a significant relationship between $\mathrm{HP}$ positivity and IM development, as well as studies that suggest that there is no significant relationship between HP positivity and IM development consistent with our study. The most important risk factor for the development of IM in our study was male sex above 50 years.
\end{abstract}

Key words: Endoscopy, gastrointestinal system, intestinal metaplasia, helicobacter pylori.

\section{GİRİ̧̧}

Dünya Sağllk Örgütü (WHO) verilerine göre kanser küresel olarak ikinci en s1k ölüm nedenidir ve 2015 yılında 8.8 milyon ölüm açıklanmıștır. Bunlardan
Öz

Amaç: Bu çalışmada dispeptik yakınmaları nedeniyle üst gastrointestinal system (GİS) endoskopisi yapilan hastalarda helicobacter pylori (HP) ile intestinal metaplazi (IM) arasındaki ilişkinin ortaya konulması amaçlanmıștır.

Gereç ve Yönetim: Bu çalışmaya üst GİS endoskopisi yapılan 15-84 yaş arası hastalar dahil edildi. Hastaların demografik olarak yaş ve cinsiyetleri ile histopatolojik olarak IM ve HP skorları kaydedildi. Hastalar 15-49 yaş arası ve 50 yaş üstü olmak üzere sırasıyla Grup A ve Grup B olmak üzere iki gruba ayrıldı. İM ve HP skorları arasında çeşitli değişkenlere göre korelasyon olup olmadığı araştırıldı.

Bulgular: Bu çalışmaya 15-84 yaş arası 200 hasta dahil edildi. Grup B'deki hastalarda IM görülme oranı istatiksel olarak anlamlı düzeyde yüksekti. HP negatif olan hastalarda ise; Grup B'deki hastalarda IM oranı, Grup A'ya göre anlamlı olarak yüksekti. Grup B'deki erkek hastalarda IMS hafif ve orta görülme oranı istatiksel olarak anlamlı düzeyde yüksekti.

Sonuç: Literatürde HP pozitifliği ile İM gelişimi arasında anlamlı bir ilişki olduğunu gösteren çalışmaların yanısıra bu çalışmamızla uyumlu olarak HP pozitifliği ile IM gelişimi arasında anlamlı bir ilişki olmadığını bildiren çalışmalar da bulunmaktadır. Çalışmamızda İM gelişimi için en önemli risk faktörünün 50 yaş üzeri erkek cinsiyet olduğu sonucuna varılmıştır.

Anahtar kelimeler: Endoskopi,gastrointestinal system ,intestinal metaplazi, helicobacter pylori.

mide kanseri erkeklerde dördüncü, kadınlarda ise beşinci en sık görülen kanser tipidir ${ }^{1}$. Bazı kronik enfeksiyonlar kanser için risk faktörleridir ve ortadüșük gelirli ülkelerde büyük önem arz etmektedir. 2012 yllında tanı konulan kanserlerin yaklaşık 
\%15'inde helicobacter pylori (HP), Human papillomavirus (HPV), Hepatit B virus, Hepatit C virüs ve Epstein-Barr virüsü içeren karsinojenik enfeksiyonların katk1 sağladığ ${ }^{\prime}$ belirtilmektedir ${ }^{1,2}$. Intestinal metaplazi (IM) de gastrik kanser gelişiminde prekanseröz bir lezyon olarak kabul edilmektedir. $\mathrm{Bu}$ nedenle retrospektif çalışmalarda sıklı̆̆ının ortaya konulmasının gastrik kanser erken tanı ve sağkalım üzerine katk1 sağlayacağı belirtilmektedir ${ }^{3}$.

$\mathrm{Bu}$ çalışmada dispeptik yakınmaları nedeniyle üst GIS endoskopisi yapılan 50 yaş altı ve üstü hastaların intestinal metaplazi skoru (IMS) ve helicobacter pylori skoru (HPS) açısından karșılaștırılması ve IMS ile HPS arasındaki ilișkinin ortaya konulması planland.

\section{GEREÇ VE YÖNTEM}

Bu çalışmada 01 Ocak-15 Temmuz 2017 tarihleri arasında Üst GİS endoskopisi yapılan hastalar retrospektif olarak incelendi. Bu çalışmaya üst GİS endoskopisi yapılan 15-84 yaş arası hastalar dahil edildi. Hastaların demografik olarak yaş ve cinsiyetleri ile histopatolojik olarak IMS ve HPS'ları kaydedildi. Hastalar 15-49 yaş arası ve 50 yaş üstü olmak üzere sirasiyla Grup A ve Grup B olmak üzere iki gruba ayrildı. Antrumdan alınan biyopsi örneklerinin histopatolojik incelemesi sonucu IMS ve HPS'lar1 șiddetine göre 0'dan 3'e kadar derecelendirildi. IMS ve HPS; $0=$ yok, $1=$ hafif, 2=orta, 3=şiddetli olarak değerlendirildi. Gruplar arasında IMS ve HPS skoru açısından istatiksel olarak anlamlı fark olup olmadığı, grup içinde IMS ve HPS arasında korelasyon olup olmadığı, gruplar arasında kadın ve erkek hastalar arasında IMS ve HPS skoru açısından istatiksel olarak anlamlı fark olup olmadığ1 ve grup içinde kadın ve erkek hastalar arasinda IMS ve HPS skoru korelasyon olup olmadığı araştırıldı. Endoskopi Ünitesinde en az 8 saat açlık sonrası sedo-anestezi altında (propofol) endoskopi cihazı ile orofarinksten duedonum 2. kıtaya kadar tüm üst GİS mukozası direkt görüş altında incelendi. Tüm hastalardan antral mukozal biyopsi alınd.

\section{İstatistiksel analiz}

Çalışmada elde edilen bulgular değerlendirilirken, istatistiksel analizler için SPSS 24.0 İstatistik paket programı kullanıldı. Çalışma verileri değerlendirilirken tanımlayıcı istatistiksel metotları
(Frekans, Yüzde) kullanıldı. Gruplar arası fark1 incelenmek için Pearson Ki-Kare testi; grup içi korelasyonu incelemek için ise Kendall Tau C katsayısı kullanıldı. Sonuçlar \% 95 güven aralığında, $\mathrm{p}<0,05$ anlamlılık düzeyinde değerlendirildi.

\section{BULGULAR}

Bu çalışmaya 15-84 yaş arası 200 hasta dahil edildi. Yaşlarına göre oluşturulan 2 gruptan, Grup A'da 131, Grup B'de ise 61 hasta yer ald. İki grup arasında cinsiyet açısından istatiksel olarak anlamlı fark tespit edilmedi $(p=0.198>0,05)$. Gruplara göre cinsiyet dağılımı Tablo 1'de gösterildi.

Tablo 1. Gruplara göre cinsiyet dağılımı

\begin{tabular}{|l|c|c|c|c|}
\hline Cinsiyet & $\begin{array}{c}\text { Group } \\
\mathbf{A} \\
\mathbf{n} \%\end{array}$ & $\begin{array}{c}\text { Group } \\
\mathbf{B} \\
\mathbf{n} \%\end{array}$ & $\begin{array}{c}\text { Toplam } \\
\mathbf{n} \text { \% }\end{array}$ & $\mathbf{p}^{*}$ \\
\hline Kadın & $80(57.6)$ & $41(67.2)$ & $121(60.5)$ & 0.198 \\
\hline Erkek & $59(42.4)$ & $20(32.8)$ & $79(39.5)$ & \\
\hline
\end{tabular}

*Pearson Chi-Square için anlamllık değeri

Grup A'daki hastaların 131 (\%94,2)'inde IMS yok, 5 $(\% 3,6)$ 'inde IMS hafif, $3(\% 2,2)$ 'ünde IMS orta düzeyde tespit edildi. Grup B'deki hastaların 46 $(\% 75,4)$ 'sinda IMS yok, $7(\% 11,5)$ 'sinde IMS hafif, $8(\% 13,1)$ 'inde IMS orta düzeyde tespit edildi. Grup B'deki hastalarda IMS hafif ve orta görülme oranı istatiksel olarak anlamlı düzeyde yüksekti $(p=0.000<0,05)$.

Tablo 2. Gruplara Göre IMS ve HPS Dağılımı

\begin{tabular}{|l|l|l|l|}
\hline & $\begin{array}{l}\text { Grup A } \\
\text { n \% }\end{array}$ & $\begin{array}{l}\text { Grup B } \\
\text { n \% }\end{array}$ & p* \\
\hline IMS Yok & 13194,2 & 4675,4 & $\mathbf{0 , 0 0 0}$ \\
\hline Hafif & 53,6 & 711,5 & \\
\hline Orta & 32,2 & 813,1 & \\
\hline HPS Yok & 7654,7 & 3659,0 & 0,291 \\
\hline Hafif & 2014,4 & 1219,7 & \\
\hline Orta & 4129,5 & 1118,0 & \\
\hline Şiddetli & 21,1 & 23,3 & \\
\hline
\end{tabular}

*Pearson Chi-Square için anlamlılık değeri, IMS: İntestinal metaplazi skoru HPS: Helikobakter pilori skoru.

HPS açısından Grup A ile Grup B arasında istatiksel olarak anlamlı fark tespit edilmedi $(p=0.291>0,05)$. Gruplara göre IMS ve HPS dağılımı Tablo 2'de gösterildi. Şiddetinden bağımsız olarak HP pozitifliği Grup A'da \%45.3, Grup B'de \%41, tüm hastalarda $\% 44$, İM pozitifliği Grup A'da \%5.8, Grup B'de ise 
\%24.6, tüm hastalarda \%11.5 olarak tespit edildi. HP pozitif olanlarda İM pozitifliği ise Grup A'da \%7.9, Grup B'de \%16, tüm hastalarda ise \%10.2 olarak tespit edildi. HP negatif olanlarda IM pozitifliği ise Grup A'da \%3.9, Grup B’de \%30.6, tüm hastalarda ise $\% 12.5$ olarak tespit edildi.

Şiddetinden bağımsız olarak HP pozitifliği açısından iki grup arasinda anlamlı fark yoktu $(\mathrm{p}>0,05)$. Grup B'deki hastalarda IM pozitifliği, Grup A'ya göre anlamlı olarak yüksekti $(p=0,000)$. Grupların IM ve HP pozitifliği Tablo 3'te gösterildi.

Tablo 3. Grupların İM ve HP pozitifliği

\begin{tabular}{|l|l|l|l|}
\hline $\mathrm{n}(\%)$ & Grup A & Grup B & $\mathrm{p}$ \\
\hline IM varlığ1 & $8(5.8)$ & $15(24.6)$ & $\begin{array}{l}\mathrm{x}^{2}=14.777 \\
\mathrm{p}=0.000\end{array}$ \\
\hline HP varlığ1 & $63(45.3)$ & $25(41.0)$ & $\begin{array}{l}\mathrm{x}^{2}=0.324 \\
\mathrm{p}=0.569\end{array}$ \\
\hline
\end{tabular}

Tablo 4. HP hastalarda İM pozitifliği

\begin{tabular}{|c|c|c|c|}
\hline HP Pozitif & $\begin{array}{l}\text { Grup A } \\
(\mathrm{n} \%)\end{array}$ & $\begin{array}{l}\text { Grup B } \\
(\mathrm{n} \%)\end{array}$ & P* \\
\hline IMS Yok & 5892.1 & 2184.0 & $x^{2}=1.267$ \\
\hline Var & $\begin{array}{ll}5 & 7.9 \\
\end{array}$ & $\begin{array}{ll}4 & 16.0 \\
\end{array}$ & $\mathrm{p}=0.260$ \\
\hline \multicolumn{4}{|l|}{ HP Negatif } \\
\hline HPS Yok & 7396.1 & $25 \quad 69.4$ & $x^{2}=15.813$ \\
\hline Var & $\begin{array}{ll}3 & 3.9\end{array}$ & 1130.6 & $\mathrm{p}=0.000$ \\
\hline
\end{tabular}

HP pozitif hastalarda İM pozitifliği açısından 2 grup arasinda anlamlı fark tespit edilmedi $(\mathrm{p}>0,05)$. HP negatif olan hastalarda ise; Grup B'deki hastalarda IM oranı, Grup A'ya göre anlamlı olarak yüksekti $(p=0,000)$. HP pozitif ve negatif hastalarda IM pozitifliği Tablo 4'te gösterildi.Kadın hastalarda, IMS ve HPS açısından Grup A ile Grup B arasında istatiksel olarak anlamlı anlamlı tespit edilmedi ( $>0,05)$. Kadın hastalarda gruplara göre IMS ve HPS dağılımı Tablo 5'te gösterildi.

Tablo 5. Kadın hastalarda gruplara göre IMS ve HPS dağılımı

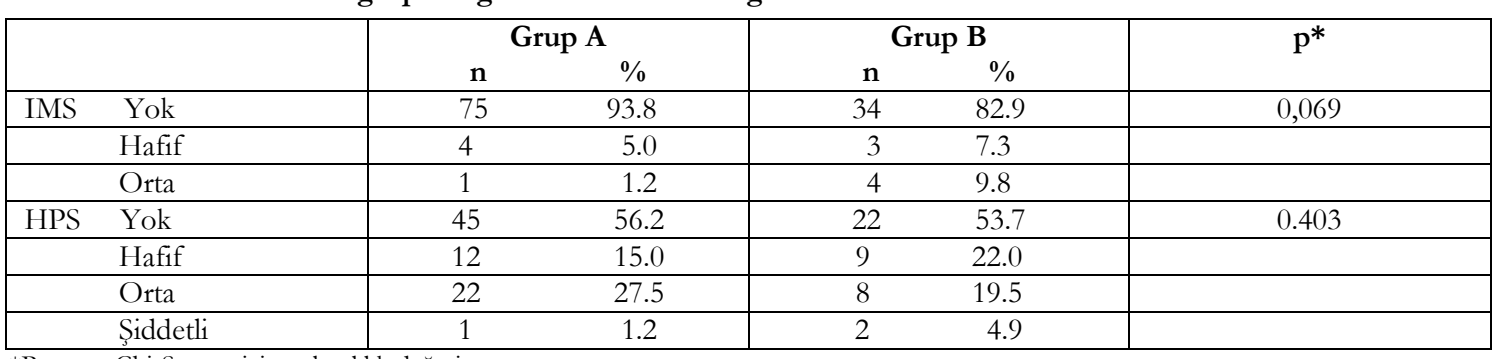

*Pearson Chi-Square için anlamlılık değeri

Erkek hastalarda, Grup A'daki hastaların $56(\% 94,9)$ 'sinda IMS yok, 1 (\%1,7)'inde IMS hafif, 2 $(\% 3,4)$ 'sinde IMS orta düzeyde tespit edildi. Grup B'deki hastaların $12(\% 60,0)$ 'sinde IMS yok, 4 $(\% 20,0)$ 'ünde IMS hafif, $4(\% 20,0)$ 'ünde IMS orta düzeyde tespit edildi. Grup B'deki erkek hastalarda
IMS hafif ve orta görülme oranı istatiksel olarak anlamlı düzeyde yüksekti $(\mathrm{p}=0,000<0,05)$. Erkek hastalarda, HPS açisından Grup A ile Grup B arasında istatiksel olarak anlamlı fark yoktu. $(p=0,291>0,05)$. Erkek hastalarda gruplara göre IMS ve HPS dağılımı Tablo 6'te gösterildi.

Tablo 6. Erkek hastalarda gruplara göre IMS ve HPS

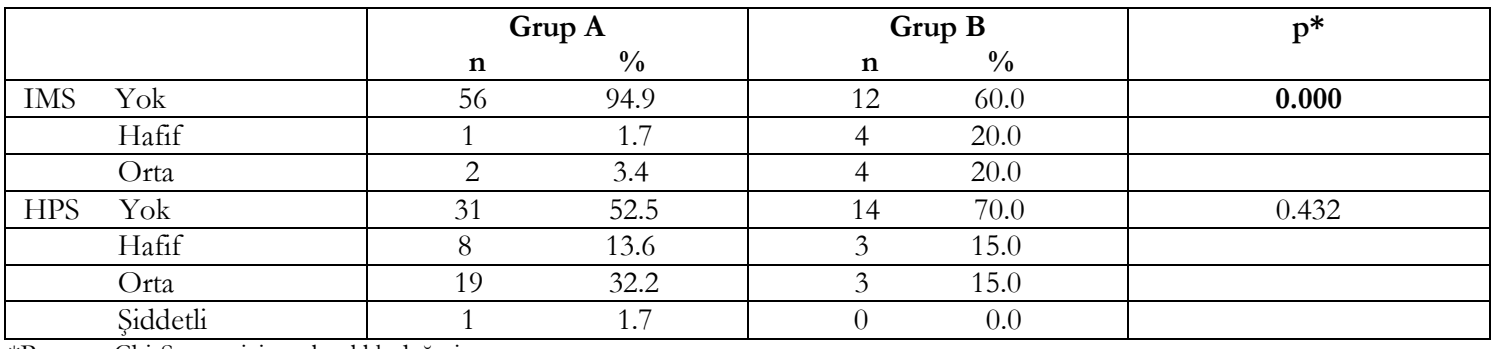

*Pearson Chi-Square için anlamlılık değeri 
Tablo 7. Grup A'daki hastalarda cinsiyete göre IMS ile HPS ilişkisi

\begin{tabular}{|c|ccc|cc|c|}
\hline & & \multicolumn{2}{|c|}{ Kadin } & \multicolumn{2}{c|}{ Erkek } & $\mathbf{p}^{*}$ \\
\hline HPS & Yok & $\mathbf{0}$ & $\mathbf{n}$ & $\mathbf{\%}$ & 0.933 \\
\hline Hafif & 45 & 56.2 & 31 & 52.5 & \\
\hline Orta & 12 & 15.0 & 8 & 13.6 & \\
\hline & Şiddetli & 22 & 27.5 & 19 & 32.2 & \\
\hline IMS & Yok & 1 & 1.2 & 1 & 1.7 & 0.416 \\
\hline & Hafif & 75 & 93.8 & 56 & 94.9 & \\
\hline Orta & 4 & 5.0 & 1 & 1.7 & \\
\hline
\end{tabular}

*Pearson Chi-Square için anlamlllık değeri

Grup B'de, IMS ve HPS açısından kadın ve erkek hastalar arasinda istatiksel olarak anlamlı fark tespit edilmedi ( $p>0,05)$. Grup B'deki hastalarda cinsiyete göre IMS ile HPS ilişkisi Tablo 8'de gösterildi.

Grup A'daki hastalarda HPS ile IMS arasinda istatiksel olarak anlamlı ilişki tespit edilmedi
( $>00,05)$. Grup A'daki hastalarda IMS ile HPS ilişkisi Tablo 9'da gösterildi.

Grup B'deki hastalarda HPS ile IMS arasinda istatiksel olarak anlamlı ilişki tespit edilmedi ( $>0,05)$. Grup B'deki hastalarda IMS ile HPS ilişkisi Tablo 10'da gösterildi.

Tablo 8. Grup B'daki hastalarda cinsiyete göre IMS ile HPS ilişkisi

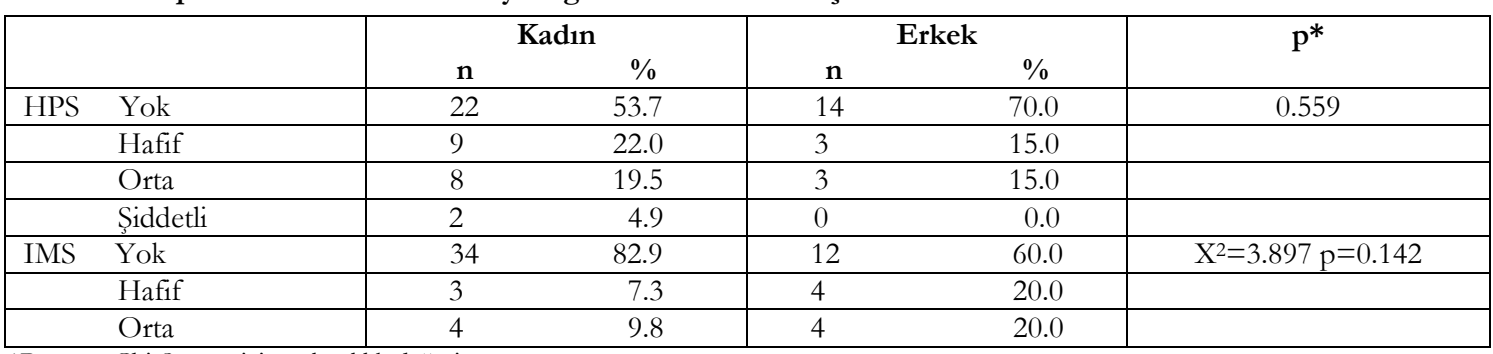

*Pearson Chi-Square için anlamlılık değeri

Tablo 9. Grup A'daki hastalarda IMS ile HPS ilişkisi

\begin{tabular}{|ll|rr|rr|rr|c|}
\hline IMS & & \multicolumn{2}{|c|}{ Yok } & \multicolumn{2}{c|}{ Hafif } & \multicolumn{2}{c|}{ Orta } & \multirow{2}{*}{ p $^{*}$} \\
& & $\mathbf{n}$ & $\mathbf{0}$ & $\mathbf{n}$ & $\mathbf{\%}$ & $\mathbf{n}$ & $\mathbf{\%}$ & \\
\hline HPS & Yok & 73 & 55.7 & 3 & 60.0 & 0 & 0.0 & 0.204 \\
\hline & Hafif & 20 & 15.3 & 0 & 0.0 & 0 & 0.0 & \\
\hline Orta & 36 & 27.5 & 2 & 40.0 & 3 & 100 & \\
\hline & Şiddetli & 2 & 1.5 & 0 & 0.0 & 0 & 0.0 & \\
\hline
\end{tabular}

*Kendall Tau c için anlamlılık değeri

Tablo 10. Grup B'daki hastalarda IMS ile HPS ilişkisi

\begin{tabular}{|c|c|c|c|c|c|c|c|c|}
\hline \multirow{2}{*}{\multicolumn{2}{|c|}{ IMS }} & \multicolumn{2}{|c|}{ Yok } & \multicolumn{2}{|c|}{ Hafif } & \multicolumn{2}{|c|}{ Orta } & \multirow[t]{2}{*}{$\mathrm{p}^{*}$} \\
\hline & & $\mathrm{n}$ & $\%$ & $\mathbf{n}$ & $\%$ & $\mathrm{n}$ & $\%$ & \\
\hline HPS & Yok & 25 & 54.3 & 5 & 71.4 & 6 & 75.0 & 0.240 \\
\hline & Hafif & 11 & 23.9 & 0 & 0,0 & 1 & 12.5 & \\
\hline & Orta & 8 & 17.4 & 2 & 28.6 & 1 & 12.5 & \\
\hline & Şiddetli & 2 & 4.3 & 0 & 0.0 & 0 & 0.0 & \\
\hline
\end{tabular}

*Kendall Tau c için anlamlılık değeri 


\section{TARTIŞMA}

HP genel popülasyonun \%50'sinde görülen midede lokalize olan Gram negatif bir bakteridir ${ }^{4,5}$. HP peptik ülser, mide kanseri ve mukoza ilişkili lenfoid doku lenfoma (MALTOMA) gelişimi ile ilişkilidir ${ }^{4,6}$. Mide kanseri kronik HP infeksiyonunda atrofik gastrit, intestinal metaplazi ve displazi evrelerinden geçerek gelişir ${ }^{4,7}$. Şiddetli atrofik gastrit ve IM mide ülseri ve kanseri için iyi bilinen risk faktörleridir ${ }^{4,8}$. IM gastrik mukoza ve gland epitelinin morfolojik olarak intestinal epitele benzer değişiklikler göstermesidir ${ }^{3}$. Histopatolojik ve histokimyasal özelliklerine göre 3 tipe ayrılır. Tip 1 (komplet); sialomüsin, Tip 2 (inkomplet); gastrik ve intestinal müsin, Tip 3 (inkomplet); ise sülfomüsin salg1lar ${ }^{3,9}$. Literatürdeki çalışmalarda IM subtipi ve yaygınlığı ile gastrik karsinom arasinda korelasyon olduğu bildirilmektedir ${ }^{3,10,11}$. Tip 3 IMM'de gastrik karsinom gelişme riskinin en yüksek olduğu belirtilmektedir ${ }^{10}$. IM gelişiminde ise en önemli risk faktörünün HP olduğu belirtilmekle birlikte HP pozitifliğinin IM gelişimi üzerine etkileri ile ilgili tartışmalar devam etmektedir 3 ,12,13. Bu çalışmamızda gerek iki grup arasında gerekse gruplar içinde HPS ile IMS arasında anlamlı bir ilişki tespit edilmedi. Ayrıca şiddetinden bağımsız olarak ta HP pozitif olanlarda IMM pozitifliği açısından iki grup arasında anlamlı fark tespit edilmedi. Literatürdeki bazı çalışmaların aksine bu çalışmada elde edilen veriler HP varlığının IM gelişimi için risk faktörü olduğu bilgisini desteklememektedir. Literatürdeki bazı çalışmalarda HP eradikasyonunun histopatolojik olarak IM'de anlamlı regresyon olduğunu bildiriken bazı çalışmalarda ise anlamlı bir düzelme olmadığı bildirilmektedir ${ }^{3,14-18}$. Bu nedenle konu ile ilgili tartışmalar hala güncelliğini korumaktadır. Dolayısıyla daha geniş kapsamlı çalışmalara ihtiyaç duyulmaktadır. IM gelişimi için diğer risk faktörleri ise sigara, sosyoekonomik durum, tütsülenmiş-tuzlu gıda tüketimi, yaş, cinsiyet, etnik yap1, immun yanıt ve genetik faktörlerdir $3,12,13$.

Craanen ve arkadaşları 19 tarafindan 533 hastada yapılan çalışmada 50 yaş altındaki hastalarda HP pozitifliği \%46,6, 50 yaş ve üzerindeki hastalarda ise $\% 57,6$ olarak rapor edilmiştir. Craanen ve arkadaşları tarafindan yapılan çalışmanın aksine çalışmamızda 50 yaş ve üzeri hastalarda HP pozitifliği 50 yaş altı hastalara göre daha düşük bulunmuştur. IM pozitifliği ise Craanen ve arkadaşları tarafindan yapılan çalışmada 50 yaş altındaki hastalarda IM pozitifliği \%10.4, 50 yaş ve üzerindeki hastalarda ise
\%31.9 olarak rapor edilmiştir. İM pozitifliği açısından çalışmamızın sonuçları Craanen ve arkadaşları tarafindan yapılan çalışma sonuçları ile uyumlu bulunmuştur. Çalışmamızdaki sonuçlara göre 50 yaş ve üzerinin İM gelişimi için önemli bir risk faktörü olduğu görülmektedir. Ajdarkosh ve arkadaşları 20 tarafindan 688 hastada yapılan çalışmada İM oranı \%19.8, HP oranı \%64.5 olarak bildirilmiştir. Bu çalışmamızda ise Ajdarkosh et al. tarafindan yapılan çalışmaya göre IM ve HP oranı daha düşük olarak tespit edilmiştir (İM:\%11.5, HP:\%44). İM gelişiminde yaşın önemli bir risk faktörü olduğu dikkate alındığında, çalışmamızda IM oranının daha düşük olmasinın Ajdarkosh et al. tarafindan yapılan çalışmanın 40 yaş üzeri hastalarda yapılmasından dolayı olduğu düşünülmektedir. Bu çalışmamızda ise 40 yaş altındaki hastalar da çalışmaya dahil edilmiştir. Çalışmamızda tüm gruplardaki hastalarda tespit edilen HP pozitiflik oranı (\%44) literatürde belirtilen genel popülasyondaki pozitiflik oranlarına yakın olarak tespit edilmiştir ${ }^{4}$. Ancak İM oranı bazı çalışmalardaki sonuçlara göre daha düşük tespit edilmiş olup, bunun çalıșmamıza genç hastaların dahil edilmesine bağlı olabileceği düşünülmektedir ${ }^{6,20}$. Çünkü çalışmamızdaki hastaların ortalama yaşı 42.97 iken, Ajdarkosh ve arkadaşları 20 tarafindan yapılan çalışmada ortalama yaş 57.87, Uemura ve arkadaşları $^{6}$ tarafindan yapılan çalışmada ise 52 olarak bildirilmektedir.

Rokkas ve arkadaşları ${ }^{21}$ tarafindan yapılan geniş kapsamlı bir meta-analizde atrofik veya non-atrofik gastrit durumunda HP eradikasyonunun primer önleyici strateji olduğu, ancak İM veya displazi varlığında ise eradikasyon tedavisinin mide kanseri için önleyici olmadığı rapor edilmiştir. Çalışmamızda HP pozitif olan tüm hastalara HP eredikasyon tedavisi uyguland. Rokkas ve arkadaşları ${ }^{21}$ tarafindan yapilan meta-analizde HP eradikasyonunun mide kanserini önlemede önemli olduğu belirtilmekle birlikte sonuçların Doğu Asya ülkelerindeki verilere göre elde edildiği dikkate alındığında diğer ülkelerin sonuçlarına gereksinim olduğu aşikârdır. Mide kanseri gelişiminde HP dişında pekçok risk faktörü olduğundan diğer ülkelerden elde edilecek veriler doğrultusunda HP eradikasyonun mide kanserini önlemede önemli olup olmadığı daha net olarak ortaya konulabilir.

Uemura ve arkadaşları ${ }^{6}$ tarafindan 1526 hasta üzerinde yapılan çalışmada HP pozitifliği ile gastrik kanser ve IM arasında anlamlı ilişki olduğu rapor 
edilmiştir. Topal ve arkadaşları ${ }^{22}$ tarafından yapılan çalışmada ise bizim çalışma sonuçlarımızla uyumlu olarak, HP yoğunluğu ile intestinal metaplazi derecesi arasında istatistiksel olarak anlamlı bir fark tespit edilmemiştir. Çalışmamızdan elde edilen sonuçlar IM gelişimi için en önemli risk faktörünün 50 yaş erkek cinsiyet olduğunu HP pozitifliği ile IM gelişimi arasında pozitif bir korelasyon olmadığını ortaya koymaktadır. Ancak bu sonuçların daha geniş kapsamlı çalışmalar ile desteklenmesi gerekir.

Sonuç olarak; WHO verilerine göre mide kanseri erkelerde 4. kadınlarda ise 5. en sik görülen kanser tipidir. 2012 verilerine göre kanser tanis1 alan hastaların \%15'inde HP'nin de olduğu bazı karsinojenik bakterilerin tespit edildiği bildirilmektedir. IM mide kanseri gelişiminde iyi bilinen bir risk faktörü olarak kabul edilmektedir. IM gelişiminde ise en önemli risk faktörünün HP olduğu belirtilmekle birlikte HP pozitifliğinin İM gelişimi üzerine etkileri ile ilgili tartışmalar devam etmektedir. Literatürde HP pozitifliği ile İM gelişimi arasında anlamlı bir ilişki olduğunu gösteren çalışmaların yanısıra bu çalışmamızla uyumlu olarak HP pozitifliği ile İM gelişimi arasında anlamlı bir ilişki olmadığını bildiren çalışmalar da bulunmaktadır. Ayrıca anlamlı ilişki olduğunu bildiren çalışmaların çoğunlukla Doğu Asya ülkelerindeki veriler olduğu dikkate alındığında diğer ülkelerdeki geniş kapsamlı çalışma sonuçlarına gereksinim olduğu düşünülmektedir. Çalışmamızda İM gelişimi için en önemli risk faktörünün 50 yaş üzeri erkek cinsiyet olduğu sonucuna varılmıștır.

\section{KAYNAKLAR}

1. World Health Organization. World Cancer Report 2014. Geneva, WHO, 2014.

2. Plummer M, de Martel C, Vignat J, Ferlay J, Bray F, Franceschi S. Global burden of cancers attributable to infections in 2012: a synthetic analysis. Lancet Glob Health. 2016;4:609-16.

3. Özer Etik D, Turhan N. Gastrik intestinal metaplaziye gastroenterolog ve patolog gözü ile bakış. Güncel Gastroenteroloji. 2016;20:375-82.

4. Sugimoto $\mathrm{M}$, Ban $\mathrm{H}$, Ichikawa $\mathrm{H}$, Sahara $\mathrm{S}$, Otsuka $\mathrm{T}$, Inatomi $\mathrm{O}$ et al. Efficacy of the Kyoto classification of gastritis in identifying patients at high risk for gastric cancer. Intern Med. 2017;56:57986.

5. Malfertheiner P, Megraud F, O'Morain CA, Atherton J, Axon AT, Bazzoli F et al. Management of Helicobacter pylori infection--the Maastricht IV/ Florence Consensus Report. Gut. 2012;61:646-64.
6. Uemura N, Okamoto S, Yamamoto S, Matsumura N, Yamaguchi S, Yamakido M et al. Helicobacter pylori infection and the development of gastric cancer. N Engl J Med. 2001;345:784-9.

7. Correa P, Haenszel W, Cuello C, Tannenbaum S, Archer M. A model for gastric cancer epidemiology. Lancet. 1975;2:58-60.

8. Graham DY. Helicobacter pylori infection in the pathogenesis of duodenal ulcer and gastric cancer: a model. Gastroenterology. 1997;113:1983-91.

9. Silva E, Teixeria A, David L, Carneiro F, Reis CA, Sobrinho-Simões J et al. Mucins as key molecules for the classification of intestinal metaplasia. Mod Pathol. 2004;17:62-74.

10. Correa P, Piazuela MB, Wilson KT. Pathology of gastric intestinal metaplasia: clinical implications. Am J Gastroenterol. 2010;105:493-8.

11. Gonzales CA, Sans-Anquela JM, Gisbert JB, Correa P. Utility of subtyping intestinal metaplasia as marker of gastric cancer risk. a review of th evidence. Int J Cancer. 2013;133:1-12.

12. Yoon H, Kim N. Diagnosis and management of the high risk group for gastric cancer. Gut Liver. 2015;9:5-17.

13. Conteduca V, Sansonna D, Lauleta G, Russi S, Ingravallo G, Dammacco F. H Pylori infection and gastric cancer: state of the art. Int $\mathrm{J}$ Oncol. 2013;42:5-18.

14. Wong BC, Lam SK, Wong WM, Chen JS, Zheng TT, Feng RE et al. Helicobacter pylori eradication to prevent gastric cancer in a high-risk region of China: a randomized controlled trial. JAMA. 2004;291:18794.

15. Fuccio L, Zagari RM, Eusebi LH, Laterza L, Cennamo V, Ceroni $\mathrm{L}$ et al. Meta-analysis: can Helicobacter pylori eradication treatment reduce the risk for gastric cancer? Ann Intern Med. 2009;151:121-8.

16. Kodama M, Murakami K, Okimoto T, Abe T, Nakagawa Y, Mizukami K et al. Helicobacter pylori eradication improves gastric atrophy and intestinal metaplasia in long-term observation. Digestion. 2012;85:126-30.

17. Kang JM, Kim N, Shin CM, Lee HS, Lee DH, Jung $\mathrm{HC}$ et al. Predictive factors for improvement of atrophic gastritis and intestinal metaplasia after Helicobacter pylori eradication: a three-year followup study in Korea. Helicobacter. 2012;17:86-95.

18. Wang J, Xu L, Shi R, Huang X, Li SW, Huang Z et al. Gastric atrophy and intestinal metaplasia before and after Helicobacter pylori eradication: a metaanalysis. Digestion. 2011;83:253-60.

19. Craanen ME, Dekker W, Blok P, Ferwerda J, Tytgat GN. Intestinal metaplasia and Helicobacter pylori: an endoscopic bioptic study of the gastric antrum. Gut. 1992;33:16-20.

20. Ajdarkosh H, Sohrabi M, Moradniani M, Rakhshani $\mathrm{N}$, Sotodeh M, Hemmasi G et al. Prevalence of 
gastric precancerous lesions among chronic dyspeptic patients and related common risk factors. Eur J Cancer Prev. 2015 ;24:400-6.

21. Rokkas T, Rokka A, Portincasa P. A systematic review and meta-analysis of the role of Helicobacter pylori eradication in preventing gastric cancer. Ann
Gastroenterol. 2017;30:414-23.

22. Topal D, Göral V, Yılmaz F. Helicobacter pylori'nin intestinal metaplazi, gastrik atrofi ve Bcl-2 ile ilişkisi. Turkiye Klinikleri J Gastroenterohepatol. 2004;15:6573. 